\title{
Acquired angioedema type 1
}

INSERM

\section{Source}

INSERM. (1999). Orphanet: an online rare disease and orphan drug data base. Acquired angioedema type 1. ORPHA:100056

Acquired angioedema type 1 (AAE 1) is a type of acquired angioedema (AAE) (see this term) characterized by acute edema in subcutaneous tissues, viscera and/or the upper airway. 